\title{
Propriedades mecânicas do cimento ósseo e da poliuretana de mamona com e sem catalisador
}

[Mechanical properties of bone cement and castor oil-based polyurethane with and without a catalyst]

\author{
A.F.M. Lima $^{1}$, S.C. Rahal ${ }^{1}$, S.S. Muller ${ }^{2}$, M.C.E. Correa ${ }^{1}$, C.R. Padovani ${ }^{3}$ \\ ${ }^{1}$ Faculdade de Medicina Veterinária e Zootecnia - UNESP \\ Distrito de Rubião Júnior $\mathrm{s} / \mathrm{n}$ \\ 18618-000 - Botucatu, SP \\ ${ }^{2}$ Faculdade de Medicina - UNESP - Botucatu, SP \\ ${ }^{3}$ Instituto de Biociências - UNESP - Botucatu, SP
}

\begin{abstract}
RESUMO
Avaliou-se o comportamento mecânico do polímero de mamona, tendo por variáveis o tempo de produção e a presença de catalisador, e utilizando como padrão comparativo o cimento ósseo (polimetilmetacrilato). Foram estabelecidos três grupos experimentais, de acordo com o tipo de corpo de prova (cilindro ou barra) e polímero utilizado, que foram posteriormente subdivididos em subgrupos conforme o tempo após produção, ou seja, 24,48 e 72 horas. O ensaio de compressão analisou a carga máxima e a tensão e o ensaio de dobramento estudou o módulo de dobramento e a resistência. Estatisticamente não houve diferenças nos valores de resistência à compressão ou ao dobramento às 24 , 48 e 72 horas após a produção do polimetilmetacrilato e da poliuretana, com ou sem catalisador. A poliuretana com catalisador foi a mais resistente nos ensaios de compressão, apresentando módulo de dobramento semelhante ao do polimetilmetacrilato e resistência ao dobramento superior à da poliuretana sem catalisador. Conclui-se que: o tempo não alterou as propriedades mecânicas dos compósitos avaliados; o catalisador melhorou o desempenho mecânico da poliuretana de mamona; na resistência mecânica à compressão, a poliuretana com catalisador suportou mais carga que o polimetilmetacrilato.
\end{abstract}

Palavras-chave: polímero de mamona, biomaterial, resistência mecânica, resina acrílica

\begin{abstract}
The mechanical properties of castor oil-based polyurethane was evaluated considering post-production time and the presence of a catalyst as variables and using bone cement (polymethylmetacrylate) as a comparative pattern. According to proof body type (cylinders or bars) and the used polymer, three experimental groups were established. Such groups were later subdivided according to post-production time, namely, 24, 48, and 72 hours. A compression assay analyzed maximum load and tension, and a folding assay evaluated the folding module and resistance. There were no statistical differences in the values for resistance to compression or folding at 24, 48, and 72 hours after the production of polymethylmetacrylate and polyurethane with or without a catalyst. Castor oil-based polyurethane with a catalyst showed to be the most resistant during the compression assays as its folding module was similar to that of polymethylmetacrylate, and its folding resistance was higher than that of polyurethane without a catalyst. In conclusion, time did not change the mechanical properties of the evaluated composites; the catalyst improved the mechanical performance of castor oil-based polyurethane; castor oil-based polyurethane with a catalyst supported more load during the assay for mechanical resistance to compression than did polymethylmetacrylate.
\end{abstract}

Keywords: castor oil polymer, biomaterial, mechanical resistance, acrylic resin

Recebido em 21 de maio de 2008

Aceito em 31 de outubro de 2008

E-mail: alflima@hotmail.com 


\section{INTRODUÇÃO}

O cimento ósseo polimetilmetacrilato é amplamente utilizado em procedimentos ortopédicos, seja para a fixação de próteses ou parafusos ao osso, para a estabilização de vértebras em pacientes osteoporóticos, ou como material preenchedor de cavidades ósseas e defeitos cranianos (Fukushima et al., 2002; Nussbaum et al., 2004; Frazer et al., 2005). Alguns problemas associados ao produto são a osteonecrose induzida no momento da polimerização e as reações tipo corpo estranho (Lintner et al., 1982; Fukushima et al., 2002). Além disso, a resistência do material é dependente não apenas de sua composição química, mas da forma como é misturado e manipulado, da forma de aplicação, da temperatura local e da presença de outras substâncias a ele incluídas, tais como antibióticos ou produtos radiopacos (Demian e McDermott, 1998; Lewis, 1999; Nussbaum et al., 2004).

No ano de 1984 foi divulgado o desenvolvimento da poliuretana vegetal, derivada do óleo extraído de sementes da mamona, pelo grupo de Química Analítica e Tecnologia de Polímeros da Universidade de São Paulo (Ignácio et al., 1996). Por ser um produto versátil, pode ser preparado previamente com diferentes consistência e forma ou utilizado no momento da intervenção cirúrgica (Ignácio et al., 1996; Bioosteo, 2006). Entre as suas indicações clínicas incluem-se a fixação de próteses, a reconstituição e o preenchimento de espaços ósseos (Bioosteo, 2006), sendo em algumas situações uma alternativa ao polimetilmetacrilato. Ressalta-se que a maioria das publicações referentes ao emprego do polímero de mamona está associada a estudos in vivo, que analisaram biocompatibilidade, capacidade de estimulação na neoformação óssea, osteointegração e toxicidade (Kfuri et al., 2001; Rezende et al., 2001; Ignácio et al., 2002; Ziliotto et al., 2003; Laranjeira et al., 2004; Bolson et al., 2005; Pereira-Júnior et al., 2007), mas há poucos relatos sobre suas propriedades mecânicas (Claro Neto, 1997; Kfuri et al., 2001; Silva et al., 2001; Ferneda et al., 2006).

Dessa forma, o objetivo deste trabalho foi avaliar o comportamento mecânico do polímero de mamona, quanto à carga máxima e à tensão à compressão, ao módulo e à resistência ao dobramento, tendo por variáveis o tempo de produção e a presença de catalisador, e utilizando como padrão comparativo o polimetilmetacrilato.

\section{MATERIAL E MÉTODOS}

Foram estabelecidos grupos experimentais, de acordo com o tipo de corpo de prova (cilindro ou barra) e polímero utilizado, que foram posteriormente subdivididos em subgrupos conforme o tempo após sua produção, ou seja, 24,48 e 72 horas.

Para os corpos de prova cilíndricos, foram constituídos três grupos, a saber: grupo $1(n=30)$ - polimetilmetacrilato (PMMA) com subgrupos de 10 unidades cada (PMMA24, PMMA48 e PMMA72 horas); grupo $2(n=30)$ - poliuretana derivada do óleo de mamona sem catalisador (BO) com subgrupos de 10 unidades cada (BO24, BO48 e BO72 horas); grupo $3(n=30)$ poliuretana derivada do óleo de mamona com catalisador (PC) com subgrupos de 10 unidades cada (PC24, PC48 e PC72 horas).

Para os corpos de prova em forma de barra, foram constituídos três grupos, a saber: grupo $1(n=21)$ polimetilmetacrilato (PMMA) com subgrupos de sete unidades cada (PMMA24, PMMA48 e PMMA72 horas); grupo $2(\mathrm{n}=21)$ - poliuretana derivada do óleo de mamona sem catalisador (BO) com subgrupos de sete unidades cada (BO24, BO48 e $\mathrm{BO} 72$ horas); grupo $3(\mathrm{n}=21)$ - poliuretana derivada do óleo de mamona com catalisador (PC) com subgrupos de sete unidades cada (PC24, PC48 e PC72 horas).

Todos os corpos de prova foram confeccionados por um mesmo técnico nos laboratórios da indústria biomecânica $^{1}$, em sala climatizada na temperatura de $23^{\circ} \mathrm{C}$, com base na norma ISO 5833. Para a produção dos corpos de prova em forma de cilindros, foi utilizada uma matriz de polietileno dotada de quatro cavidades com $12 \mathrm{~mm}$ de comprimento e $6 \mathrm{~mm}$ de diâmetro, e para os em forma de barra empregou-se uma matriz de polietileno dotada de três cavidades de $75 \mathrm{~mm}$ de comprimento e $65 \mathrm{~mm}$ de largura e $3,3 \mathrm{~mm}$ de espessura. Utilizou-se cimento ósseo ${ }^{2}$ radiopaco de baixa viscosidade, com tempo de adesividade de três a cinco minutos e tempo de polimerização em média de 15 minutos. O componente líquido constituiu-se de metilmetacrilato $(98,215 \%)$, nn dimetil-p-toluidina $\quad(0,816 \%)$ álcool etílico $(0,945 \%)$, ácido ascórbico $(0,022 \%)$ e hidroquinona

\footnotetext{
${ }^{1}$ Biomecânica Ind. e Com. de Produtos Ortopédicos Ltda. Jaú, SP - Brasil.

${ }^{2}$ Cimento ortopédico Biomecânica - Biomecânica Ind. e Com. de Produtos Ortopédicos Ltda. - Jaú, SP - Brasil.
} 
$(0,002 \%)$ e o componente pó de polimetilmetacrilato $(87,5 \%)$, sulfato de bário $(10,0 \%)$ e peróxido de benzoil (2,50\%). A poliuretana derivada do óleo de mamona sem catalisador $\left(\mathrm{BO}^{3}\right)$ compunha-se de pré-polímero $(34,5 \%)$, poliol $(31 \%)$ e carbonato de cálcio $(34,5 \%)$, com densidade final de $0,068 \mathrm{~g} / \mathrm{cm}^{3}$, e a poliuretana derivada do óleo de mamona com catalisador (PC) de pré-polímero $(38,5 \%)$, poliol $(27 \%)$, carbonato de cálcio $(34,5 \%)$ e catalisador $(0,05 \%)$, com densidade final de $0,085 \mathrm{~g} / \mathrm{cm}^{3}$.

Os ensaios foram efetuados em Máquina Universal de Ensaios Mecânicos ${ }^{4}$ (EMIC DL 10000), com a seguinte padronização: célula de carga de $5000 \mathrm{~N}$; sentido compressão; velocidade de aplicação da carga de $20 \mathrm{~mm} / \mathrm{min}$ para os ensaios de resistência à compressão, e $5 \mathrm{~mm} / \mathrm{min}$ para ensaios de resistência ao dobramento, conforme especificado pela norma ISO 5833:1992.

Cada cilindro utilizado para o ensaio de compressão foi colocado entre dois suportes metálicos apoiados numa base de madeira. O cabeçote proximal da máquina de ensaio foi movimentado, promovendo compressão axial do corpo de prova até ocorrer cisalhamento. A carga e a deformação foram obtidas no limite de resistência máxima à compressão, com o auxílio de software do equipamento. $\mathrm{O}$ índice de rigidez (coeficiente de proporcionalidade) correspondeu à tangente física da inclinação da curva e na base linear do diagrama: carga versus deformação. A deformação percentual foi calculada dividindo-se o valor da deformação pelo comprimento inicial do corpo de prova.

Cada barra utilizada nos ensaios de dobramento foi montada sobre suporte de madeira, com apoio em dois pontos, que continha no ponto médio um sensor de deslocamento adaptado ao relógio controlador. No cabeçote proximal da máquina de ensaio, foi rosqueada uma peça de aço inoxidável com dois pontos para aplicação da carga, o que configurou a montagem para ensaio em flexão em quatro pontos. O módulo de dobramento foi calculado pelo diagrama cargadeformação, em que foram efetuadas as deflexões de $15 \mathrm{~N}$ e $50 \mathrm{~N}$. Para o cálculo dos valores do módulo de dobramento (E), foi utilizada a equação:

\footnotetext{
${ }^{3}$ BIOOSTEO - Biomecânica Ind. e Com. de Produtos Ortopédicos Ltda.- Jaú, SP - Brasil.

${ }^{4}$ EMIC Equipamentos e Sistemas de Ensaio Ltda. - São José dos Pinhais, PR - Brasil.
}

$\mathrm{E}=\frac{\Delta \mathrm{Fa}}{4 \mathrm{fbh}^{3}}\left(3 \mathrm{l}^{2}-4 \mathrm{a}^{2}\right)$, em que:

$\Delta \mathbf{F}$ é a faixa de carga $(50 \mathrm{~N}-15 \mathrm{~N}=35 \mathrm{~N})$; a é a distância entre os pontos de carga internos e externos $(20 \mathrm{~mm})$; f é a diferença entre as deflexões sob as cargas de $15 \mathrm{~N}$ e $50 \mathrm{~N}$, em milímetros; h é a espessura média da barra, em milímetros; b é a largura média da barra, em milímetros; l é a distância entre os pontos de carga externos $(60 \mathrm{~mm})$.

Para o cálculo dos valores da resistência ao dobramento (B), para cada corpo de prova utilizouse a seguinte expressão:

$\mathrm{B}=\underline{3 \mathrm{Fa}}$, em que:

$$
\mathrm{bh}^{2}
$$

F é a força de medida na queda, em Newtons; a é a distância entre os pontos de carga internos e externos $(20 \mathrm{~mm})$; b é a largura média da barra, em $\mathrm{mm}$; h é a espessura média da barra, em milímetros.

Os dados obtidos foram submetidos à análise estatística, sendo considerado nível de significância $\mathrm{P}<0,05$. Para o ensaio em compressão, foi utilizada a análise de variância não-paramétrica para o modelo com dois fatores e respectivo teste de comparações múltiplas (Norman e Streiner, 1994) das variáveis carga máxima $(\mathrm{N})$ e tensão $(\mathrm{MPa})$. Para o ensaio em dobramento, foi efetuada a análise de variância para o modelo com dois fatores, complementada com o teste de comparações múltiplas de Tukey, das variáveis módulo de dobramento $(\mathrm{MPa})$ e resistência $(\mathrm{MPa})$ (Zar, 1999).

\section{RESULTADOS}

Como a poliuretana derivada do óleo de mamona rapidamente adquire o estado adesivo, a maior dificuldade encontrada foi no preenchimento das cavidades cilíndricas da matriz de polietileno. Isto exigiu a produção de um maior número de corpos de prova, que se adequassem às exigências necessárias aos testes mecânicos, ou seja, às dimensões padronizadas. Não foram verificadas diferenças de manipulação entre a poliuretana com ou sem catalisador.

Os valores de carga máxima e tensão à compressão, módulo de dobramento e resistência ao dobramento encontram-se nas Tab. 1, 2, 3 e 4, respectivamente. 


\section{Lima et al.}

Tabela 1. Mediana e semi-amplitude da carga máxima (N) de compressão, efetuada em corpo de prova cilíndrico, segundo os grupos e os momentos de avaliações (24, 48 e 72 horas)

\begin{tabular}{lccc}
\hline \multirow{2}{*}{ Grupo } & \multicolumn{3}{c}{ Momento } \\
\cline { 2 - 4 } & $24 \mathrm{~h}$ & $48 \mathrm{~h}$ & $72 \mathrm{~h}$ \\
\hline PMMA & $15,50 \pm 2,41 \mathrm{a}$ & $14,15 \pm 5,27 \mathrm{a}$ & $13,35 \pm 4,97 \mathrm{a}$ \\
BO & $28,44 \pm 167,14 \mathrm{ab}$ & $28,59 \pm 8,88 \mathrm{a}$ & $32,05 \pm 5,65 \mathrm{a}$ \\
PC & $143,70 \pm 22,80 \mathrm{~b}$ & $164,6016,20 \mathrm{~b}$ & $154,40 \pm 37,45 \mathrm{~b}$ \\
\hline
\end{tabular}

PMMA: polimetilmetacrilato; BO: poliuretana sem catalisador; PC: poliuretana com catalisador.

Valores seguidos por letras distintas na coluna diferem entre si $(\mathrm{P}<0,05)$.

Não houve diferença entre momentos dentro da cada grupo.

Tabela 2. Mediana e semi-amplitude da tensão (Mpa) em compressão, efetuada em corpo de prova cilíndrico, segundo os grupos e os momentos de avaliações (24, 48 e 72 horas)

\begin{tabular}{lccc}
\hline \multirow{2}{*}{ Grupo } & \multicolumn{3}{c}{ Momento } \\
\cline { 2 - 4 } & $24 \mathrm{~h}$ & $48 \mathrm{~h}$ & $72 \mathrm{~h}$ \\
\hline PMMA & $0,484 \pm 0,075 \mathrm{a}$ & $0,442 \pm 0,165 \mathrm{a}$ & $0,480 \pm 0,156 \mathrm{a}$ \\
BO & $1,006 \pm 5,910 \mathrm{ab}$ & $1,011 \pm 0,314 \mathrm{a}$ & $1,134 \pm 0,200 \mathrm{a}$ \\
PC & $4,490 \pm 0,714 \mathrm{~b}$ & $5,145 \pm 0,507 \mathrm{~b}$ & $4,826 \pm 1,171 \mathrm{~b}$ \\
\hline
\end{tabular}

PMMA: polimetilmetacrilato; BO: poliuretana sem catalisador; PC: poliuretana com catalisador.

Valores seguidos por letras distintas na coluna diferem entre si $(\mathrm{P}<0,05)$.

Não houve diferença entre momentos dentro da cada grupo.

Tabela 3. Média e desvio-padrão do módulo de dobramento, efetuado em corpo de prova tipo barra, segundo os grupos e os momentos de avaliações ( 24,48 e 72 horas)

\begin{tabular}{lccc}
\hline \multirow{2}{*}{ Grupo } & \multicolumn{3}{c}{ Momento } \\
\cline { 2 - 4 } & $24 \mathrm{~h}$ & $48 \mathrm{~h}$ & $72 \mathrm{~h}$ \\
\hline PMMA & $137,83 \pm 25,68 \mathrm{aA}$ & $208,39 \pm 68,73 \mathrm{aA}$ & $173,93 \pm 78,03 \mathrm{abA}$ \\
BO & $287,16 \pm 74,15 \mathrm{bA}$ & $541,50 \pm 184,19 \mathrm{bB}$ & $262,54 \pm 56,05 \mathrm{bA}$ \\
PC & $136,19 \pm 19,25 \mathrm{aA}$ & $196,90 \pm 30,70 \mathrm{aA}$ & $157,52 \pm 37,93 \mathrm{aA}$ \\
\hline
\end{tabular}

PMMA: polimetilmetacrilato; BO: poliuretana sem catalisador; PC: poliuretana com catalisador.

Valores seguidos por letras distintas, minúsculas na coluna e maiúsculas na linha, diferem entre si $(\mathrm{P}<0,05)$.

Tabela 4. Média e desvio-padrão da resistência ao dobramento (MPa), efetuado em corpo de prova tipo barra, segundo os grupos e os momentos de avaliações ( 24,48 e 72 horas)

\begin{tabular}{lccc} 
& \multicolumn{3}{c}{ Momento } \\
\cline { 2 - 4 } Grupo & $24 \mathrm{~h}$ & $48 \mathrm{~h}$ & $72 \mathrm{~h}$ \\
\hline PMMA & $11,61 \pm 1,57 \mathrm{cA}$ & $14,39 \pm 1,00 \mathrm{cB}$ & $12,59 \pm 2,51 \mathrm{cA}$ \\
BO & $1,25 \pm 0,14 \mathrm{aA}$ & $1,21 \pm 0,31 \mathrm{aA}$ & $1,41 \pm 0,29 \mathrm{aA}$ \\
PC & $2,59 \pm 0,35 \mathrm{bA}$ & $2,57 \pm 0,54 \mathrm{bA}$ & $2,63 \pm 0,33 \mathrm{bA}$ \\
\hline
\end{tabular}

PMMA: polimetilmetacrilato; BO: poliuretana sem catalisador; PC: poliuretana com catalisador.

Valores seguidos por letras distintas, minúsculas na coluna e maiúsculas na linha, diferem entre si $(\mathrm{P}<0,05)$.

\section{DISCUSSÃO}

As propriedades mecânicas dos cimentos são avaliadas por testes estáticos ou dinâmicos, que são definidos por normas internacionais (ISO 5833). Cargas cíclicas analisam a força de fadiga e mecanismos de quebra como a propagação da fissura (Demian e McDermott, 1998). Geralmente, as propriedades estáticas incluem estudos das forças de dobramento, compressão e tensão (Pugh e Dee, 1988; Demian e McDermott,
1998), que foram as investigadas no presente experimento.

Muitas variáveis, como a presença de sangue e outros fluidos e o acréscimo de substâncias e o método de esterilização, podem afetar as propriedades mecânicas das amostras, sendo, no entanto, a maneira de preparação dos corpos de prova uma das mais significativas quanto a esse aspecto (Demian e McDermott, 1998). Dessa forma, no presente estudo os corpos de prova foram efetuados por um único indivíduo, 
habituado à manipulação dos produtos testados, que foram misturados de acordo com a indicação do fabricante. Para o cimento acrílico, há várias formas de mistura, incluindo os métodos manuais, a vácuo e por centrifugação (Lindén e Gillquist, 1991; Smeds et al., 1997; Lewis, 1999; Geiger et al., 2001). No entanto, para a poliuretana derivada do óleo de mamona ainda é apenas descrita a preparação manual (Biosteoo, 2006). Assim, optou-se pelo emprego desse método no presente trabalho.

Durante a mistura dos componentes pó e líquido do cimento ósseo, é inevitável a inclusão de ar (Calandruccio, 1989). Esta seria uma das possíveis causas responsáveis pela formação de poros dentro dos espécimes, junto com o aquecimento do monômero e a liberação de ar da solução do monômero ou do pó (Smeds, 1997). Embora com algumas controvérsias, na dependência da dimensão, localização e distribuição dos poros podem ocorrer iniciação e propagação de fissuras, o que influenciaria no desempenho mecânico do cimento ósseo em próteses cimentadas (Ling e Lee, 1998; Janssen et al., 2005). O consenso geral é que esforços devem ser realizados para reduzir o número e o tamanho de poros ao mínimo (Demian e McDermott, 1998).

Há vários estudos associando as técnicas de mistura com o número e o tamanho dos poros do cimento (Lindén e Gillquist, 1989; Smeds et al., 1997; Lewis, 1999; Geiger et al., 2001). A maioria dos autores afirma que a mistura manual tem como resultado final um produto mais poroso em relação aos demais métodos de preparo e, conseqüentemente, com propriedades mecânicas inferiores (Lindén e Gillquist, 1989; Demian e McDermott, 1998; Nussbaum et al., 2004). Portanto, os valores obtidos nos testes de resistência mecânica efetuados no presente experimento provavelmente seriam superiores se os corpos de prova tivessem sido preparados pela mistura mecânica ou a vácuo.

Durante a mistura dos componentes básicos da poliuretana derivada do óleo de mamona, bolhas de ar são incorporadas ao produto, causando expansão da massa devido ao aumento da temperatura (Claro Neto, 1997; Bioosteo, 2006). Em virtude dessa característica, no momento da confecção dos corpos de prova foi necessária a colocação de placas metálicas sobre as matrizes, com o intuito de limitar a expansão. Vale destacar que essa expansão, não previsível, do produto pode estar associada ao elevado desviopadrão observado na análise estatística. Dessa forma, seria necessário testar outras maneiras de preparação do produto para minimizar a expansão e a porosidade, visando à maior uniformidade, especialmente se este for aplicado para a cimentação de próteses.

Estatisticamente não houve diferenças nos valores de resistência à compressão ou ao dobramento às 24, 48 e 72 horas após a produção do polimetilmetacrilato e poliuretana com ou sem catalisador, indicando que os produtos se assemelharam com relação à manutenção das forças nos períodos de observação avaliados. Conforme Calandruccio (1989), o polimetilmetacrilato na temperatura corporal adquire $80 \%$ da sua resistência em aproximadamente 15 minutos após a mistura, e a resistência final é obtida em 18 a 24 horas. Com relação à poliuretana derivada do óleo de mamona, segundo informações do fabricante (Bioosteo, 2006), o endurecimento ocorre entre 15 e 20 minutos, fato constatado durante o processamento dos corpos de prova. Por sua vez, Claro Neto (1997) afirmou que o tempo de finalização total de endurecimento da poliuretana ocorre em 48 horas.

No ensaio mecânico de compressão, a poliuretana sem catalisador apresentou-se semelhante ao polimetilmetacrilato quanto às variáveis carga máxima $(\mathrm{N})$ e tensão $(\mathrm{MPa})$. Contudo, o alto desvio-padrão, verificado em algumas das análises da poliuretana, indicou não homogeneidade de comportamento mecânico entre os corpos de prova, o que provavelmente ocorreu pela formação de bolhas de ar, como referido anteriormente. A falta de homogeneidade do produto indica que este deve ser aplicado com ressalvas nos casos de solicitação mecânica elevada.

A poliuretana com catalisador apresentou, em todos os momentos de avaliação no ensaio mecânico de compressão, maior carga máxima e tensão quando comparada à poliuretana sem catalisador e o polimetilmetacrilato, que se comportaram de forma similar $(\mathrm{P}<0,05)$. $\mathrm{O}$ aumento da resistência da poliuretana com catalisador provavelmente está relacionado à maior densidade da amostra $\left(0,085 \mathrm{~g} / \mathrm{cm}^{3}\right)$, quando comparada à sem catalisador 
$\left(0,068 \mathrm{~g} / \mathrm{cm}^{3}\right)$, segundo valores fornecidos pelo fabricante. De acordo com Lyman (1999), as variações na densidade do polímero podem refletir mudanças em cristalinidade e estereoregularidade, além de promoverem diferenças na carga do material. Ressalta-se, que em próteses cimentadas, a haste é a parte mais resistente e pode ser sujeita à quebra por fadiga sem soltura (Calandruccio, 1989). Assim, o uso de compósitos mais resistentes poderia contribuir para redução da falência da haste.

A poliuretana sem catalisador mostrou, em todos os momentos de avaliação, maior módulo de dobramento em relação à poliuretana com catalisador e o polimetilmetacrilato $(\mathrm{P}<0,01)$, que se comportaram de forma similar $(\mathrm{P}>0,05)$. Como o módulo de dobramento é caracterizado pela relação constante e proporcional entre a tensão e a deformação relativa (percentual) do material (Calandruccio, 1989; Lyman, 1999; Dee et al., 2002), observa-se que a ausência do catalisador conferiu menor elasticidade ao produto. $\mathrm{O}$ polimetilmetacrilato apresentou maior resistência ao dobramento $(\mathrm{P}<0,05)$, seguido pela poliuretana derivada do óleo de mamona com catalisador e sem catalisador. Uma vez que a resistência ao dobramento representa a carga máxima até a ruptura (Felbeck, 1971; Lyman, 1999), os resultados sugerem que o polimetilmetacrilato foi o compósito mais resistente.

Por um outro ponto de vista, a poliuretana derivada do óleo de mamona apresenta características desejáveis para as cirurgias craniofaciais e para a substituição óssea em áreas sem suporte de carga. Isto se deve ao fato de esse material ser aparentemente não degradável (Kfuri et al., 2001; Ignácio et al.; 2002; Ziliotto et al., 2003; Laranjeira et al., 2004; Bolson et al., 2005; Pereira-Júnior et al., 2007), o que permite a manter o formato, produzir poros durante a fase de expansão e possuir uma reação exotérmica não elevada (Biosteoo, 2006). Ressalta-se que em cirurgias craniofaciais a opção, em geral, é pelo polimetilmetacrilato poroso, cuja formulação se assemelha à do cimento ósseo acrescido de um gel de carboximetilcelulose biodegradável aquoso (Bruens et al., 2003). Os poros teriam a função de permitir o crescimento ósseo, resultando em provável melhora da fixação da prótese (Bruens et al., 2003). No caso da poliuretana de mamona, há estudos afirmando que os poros favorecem o crescimento de tecido osteogênico e maior fixação do implante (Cavalieri, 2000; Leonel et al., 2003). Entretanto, mais estudos são necessários, já que os poros são produzidos de forma não homogênea (Leonel et al., 2003; Bioosteo, 2006).

\section{CONCLUSÔES}

Pode-se concluir que: não há efeito do tempo nas propriedades mecânicas de compressão e dobramento em todos os compósitos avaliados; o catalisador melhora o desempenho mecânico da poliuretana de mamona; na resistência mecânica à compressão, a poliuretana com catalisador suporta mais carga que o polimetilmetacrilato.

\section{AGRADECIMENTOS}

À Coordenação de Aperfeiçoamento de Pessoal de Nível Superior - CAPES, pela bolsa de doutoramento, à Biomecânica, pelo fornecimento dos materiais e ao Conselho Nacional de Desenvolvimento Científico Tecnológico (CNPq) pela bolsa de iniciação científica.

\section{REFERÊNCIAS BIBLIOGRÁFICAS}

BIOOSTEO. 2006. Disponível em: http://www.biomecanica.com.br Acessado em: 20 dez. 2006.

BOLSON, J.; SCHOSSLER, J.E.; ORNES, R.C. et al. Clinical, radiological, macroscopical and histological analysis of domestic quail (Coturnix japonica) humerus submitted to implant of polyurethane from castor oil polymer (Ricinnus communis). Cienc. Rural, v.35, p.1123-1130, 2005.

BRUENS, M.L.; PIETERMAN, H.; de WIJN, J.R. et al. Porous polymethylmethacrylate as bone substitute in the craniofacial area. $J$. Cranifac. Surg., v.14, p.63-68, 2003.

CALANDRUCCIO, R.A. Artroplastia do quadril. In: CRENSHAW, A.H. (Ed). Cirurgia ortopédica de Campbell. São Paulo: Manole, 1989. p.1265-1564.

CAVALIERI, I. Process osseous reparation studies between the implants of mamona polymer, acrylic resin thermo activate and osseous cement in rabbit's tibias. 2000. 110f. Dissertação (Mestrado) - Faculdade de 
Odontologia, Universidade Estadual Paulista, São José dos Campos, SP.

CLARO NETO, S. Caracterizações físicoquímica de um poliuretano derivado de óleo de mamona utilizado para implantes ósseos. 1997. 127f. Tese (Doutorado) - Instituto de Química de São Carlos, Universidade de São Paulo, São Carlos, SP.

DEE， C.K.; PULEO, D.A.; BIZIOS, R. Biomaterials. In: An introduction to tissue-biomaterial interactions. New Jersey: John Wiley \& Sons, 2002. p.1-13.

DEMIAN, H.W.; McDERMOTT, K. Regulatory perspective on characterization and testing of orthopedic bone cements. Biomaterials, v.19, p.1607-1618, 1998.

DUNNE, N.J.; ORR, J.F. Curing characteristics of acrylic bone cement. J. Mater. Sci. Mater. Med., v.13, p.17-22, 2002.

FELBECK, D.K. (Ed). Introdução aos mecanismos de resistência mecânica. São Paulo: Edgard Blucher, 1971. 147p.

FERNEDA, A.B., COSTA, R.R.C.; TITA, V. et al. Compression tests of castor oil biopolymer. Mat. Res., v.9, p.327-334, 2006.

FRAZER, R.Q.; BYRON, R.T.; OSBORNE, P.B. et al. PMMA: an essential material in medicine and dentistry. J. Long Term Eff. Med. Implants, v.15, p.629-639, 2005.

FUKUSHIMA, H.; HASHIMOTO, Y.; YOSHIYA, S. et al. Conduction analysis of cement interface temperature in total knee arthroplasty. Kobe J. Med. Sci., v.48, p.63-72, 2002.

GEIGER, M.H.; KEATING, M.E.; RITTER, M.A. et al. The clinical significance of vacuum mixing bone cement. Clin. Orthop., v.382, p.258-266, 2001.

IGNÁCIO, H.; MAZZER, N.; BARBIERI, C.H. et al. Estudos sobre a aplicabilidade médica da poliuretana derivada da mamona. Resenha Ortop., v.6, p.10-12, 1996.

IGNÁCIO, H.; MAZZER, N.; BARBIERI, C.H. et al. Use of compact and porous castor oil polyurethane in the filling of bone defects. Experimental study in dogs. Rev. Bras. Ortop., v.37, p.187-194, 2002.
JANSSEN, D.; AQUARIUS, R.; STOLK, J. et al. The contradictory effects of pores on fatigue cracking of bone cement. J. Biomed. Mater. Res. $B$, v.74, p.747-753, 2005.

KFURI JR., M.; PACCOLA, C.A.J.; CHIERICE, G.O. et al. Comparison between absorbable polyparadioxanone and castor oil polyurethane pins in the fixation of distal femur osteotomies in rabbits. Rev. Bras. Ortop., v.36, p.125-131, 2001.

LARANJEIRA, M.G.; REZENDE, C.M.F.; SÁ, M.J.C. et al. Implantes de resina de poliuretana vegetal (Ricinus communis) na tração linear, fixação e fusão vertebral no cão: estudo experimental. Arq. Bras. Med. Vet. Zootec., v.56, p.602-609, 2004.

LEONEL, E.C.F.; MANGILLI, P.D.; RAMALHO, L.T.O. et al. The importance of the internal porosity of the castor bean polymer in the bone neoformation - Study in rats. Cienc. Odontol. Bras., v.6, p.19-25, 2003.

LEWIS, G. Effect of mixing method and storage temperature of cement constituents on the fatigue and porosity of acrylic bone cement. J. Biomed. Mater. Res., v.48, p.143-149, 1999.

LINDÉN, U.; GILLQUIST, J. Air inclusion in bone cement. Importance of the mixing technique. Clin. Orthop., v.247, p.148-151, 1989.

LING, R.S.M.; LEE, A.J.C. Porosity reduction in acrylic cement is clinically irrelevant. Clin. Orthop., v.355, p.249-253, 1998.

LINTNER, F.; BOSCH, P.; BRAND, G. Histological examinations of remodelling proceedings on the cement-bone surface of endoprosthesis after implantation from 3-10 years. Pathol. Res. Pract., v.173, p.376-389, 1982.

LYMAN, D.J. Polymers. In: VON RECUM, A.F. (Ed). Handbook of biomaterials evaluation. Philadelphia: Taylor \& Francis, 1999. p.37-49.

NORMAN, G.R.; STREINER, D.L. Biostatistics. The bare essentials. St Louis: Mosby Year Book, 1994. 260p.

NUSSBAUM, D.A.; GAILLOUD, P.; MURPHY, K. The chemistry of acrylic bone cements and implications for clinical use in image-guided therapy. J. Vasc. Interv. Radiol., v.15, p.121-126, 2004. 
PEREIRA-JUNIOR， O.C.M.; RAHAL， S.C.; FELISBINO, S.L. et al. Comparison between polyurethanes containing castor oil (soft segment) and cancellous bone autograft in the treatment of segmental bone defect induced in rabbits. J. Biomater. Appl., v.21, p.283-297, 2007.

PUGH, J.; DEE, R. Properties of musculoskeletal tissues and biomaterials. In: DEE, R.; MANGO, E.; HURST, L.C. (Ed). Principles of orthopaedic practice. New York: McGraw-Hill, 1988. p.134146.

REZENDE, C.M.F.; SILVA, M.C.; LARANJEIRA, M.G. et al. An experimental study of polyurethane of castor-oil plant (Ricinus communis) as a partial substitute of the common calcaneous tendon in rabbits (Oryctogalus cuniculus). Arq. Bras. Med. Vet. Zootec., v.53, p.695-700, 2001.
SILVA, R.V.; BOSE FILHO, W.W.; CHIERICE, G.O. et al. Poliuretano derivado do óleo de mamona - Tenacidade à fratura $\mathrm{e}$ morfologia da superfície de fratura. In: SIMPÓSIO EM CIÊNCIA E ENGENHARIA DE MATERIAIS, 4., 2001, São Carlos. Anais... São Carlos, 2001. p.149-150.

SMEDS, S.; GOERTZEN, D.; IVARSSON, I. Influence of temperature and vacuum mixing on bone cement properties. Clin. Orthop., v.334, p.326-334, 1997.

ZAR, J.H. Biostatistical analysis. New Jersey: Prentice Hall, 1999. 663p.

ZILIOTTO, L.; DALECK, C.R.; PADILHA FILHO, J.G. et al. A limb sparing surgery with the use of a cortical allograft preserved in glicerin: an experimental study in dogs. Acta Cir. Bras., v.18, p.107-115, 2003. 